\title{
Organic Mulching Can Suppress Litchi Downy Blight Through Modification of Soil Microbial Community Structure and Functional Potentials
}

Dandan Xu

Shenzhen Polytechnic

Jinfeng Ling

Key Laboratory of High Technology for Plant Protection of Guangdong Province

Pinggen Xi

South China Agricultural University,

Yani Zeng

Shenzhen Nanshan Xili Orchard

Jianfan Zhang

Shenzhen Nanshan Xili Orchard

Cuizhen Lan

Shenzhen Polytechnic

Zide Jiang

Key Laboratory of Microbial Signals and Disease Control

Aitian Peng

Key Laboratory of High Technology for Plant Protection of Guangdong Province

Fang Qiao ( $\nabla$ qiaofang@szpt.edu.cn )

Shenzhen Polytechnic https://orcid.org/0000-0001-7412-9278

\section{Research Article}

Keywords: Organic mulching, litchi plantation, bacterial and fungal communities, antimicrobial, litchi downy blight

Posted Date: September 2nd, 2021

DOI: https://doi.org/10.21203/rs.3.rs-852945/v1

License: (c) (i) This work is licensed under a Creative Commons Attribution 4.0 International License.

Read Full License 


\section{Abstract}

Organic mulching is an important management practice in agricultural production to improve soil quality, control crop pests and diseases and increase the biodiversity of soil microecosystem. However, the information about soil microbial diversity and composition in litchi plantation response to organic mulching and its attribution to litchi downy blight severity was limited. This study aimed to investigate the effect of organic mulching on litchi downy blight, and evaluate the biodiversity and antimicrobial potential of soil microbial community of litchi plantation soils under organic mulching. Our results showed that organic mulching could decrease the disease incidence in the litchi plantation. As a result of high-throughput 16S rRNA and ITS rDNA gene illumine sequencing, higher bacterial and fungal community diversity indexes were found in organic mulching soils, the relative abundance of norank $f$ norank o Vicinamibacterales, norank $f$ Vicinamibacteraceae, norank $f$ Xanthobacteraceae, Unclassified $c$ sordariomycetes, Aspergillus and Thermomyces were significant more than that in control soils. Isolation and analysis of antagonistic microorganism showed that 29 antagonistic bacteria strains and 37 antagonistic fungi strains were unique for mulching soils. Thus, we believe that organic mulching has a positive regulatory effect on the litchi downy blight and the soil microbial communities, and so, is more suitable for litchi plantation.

\section{Introduction}

As one important management practice in agricultural production, organic mulching is mainly used for soil improvement and environmental protection. The application of mulching derived from plant residues could not only increase water infiltration [1], prevent soil nutrient loss [2] and suppress weed germination [3], but also control crop pests and diseases $[4,5]$ and increase the biodiversity of soil microecosystem [6].

Soil microbial communities play a critical role in nutrient transformation and cycling, and soil aggregation. The diversity and structure of soil microorganism was associated with soils of varying texture, $\mathrm{N}$ content, $\mathrm{P}$ content, carbon availability and soil $\mathrm{PH}$, and changes in microbial communities and structure response to agricultural practices can be used as early indicator of soil "health" and "quality" [7, 8]. Moreover, soil microorganism was sensitive and easily affected by the changes of soil physicochemical properties created by mulching process, and close ties between the composition of soil microbial communities and mulching pattern was found [9]. Previous studies reported strong changes in richness and diversity of soil microbial community regulated by organic mulching in vegetable and tea plantation $[10,11]$.

While soil microorganism consisted of large community, such as endophytes, symbionts, pathogens, and plant growth promoting rhizobacteria. Along with improving soil health and increasing plant's responses to abiotic stress by altering defense and metabolic pathways, the soil microbiota also provides an important role in suppressing plant disease $[12,13]$. The ability of a soil to suppress disease is of key core in measuring soil productivity. There are many studies focused on the disease suppression linked to 
the soil microbial diversity. For example, the decrease of soil microbial diversity was responsible for the development of soil-borne bacterial wilt diseases of tomato [14], otherwise, the high functional redundancy in soil microbial diversity enables wilt resistance in tomato [15].

Litchi (Litchi chinensis Sonn.), a tropical and subtropical fruit species that widely cultivated in Southeast Asia. Litchi crops are subject to downy blight during blooming and fruiting stages, which leads to great economic losses $[16,17]$. Organic mulching has been reported to involved with improvement of soil physicochemical properties in litchi orchard [18]. However, to our knowledge, the information about soil microbial diversity and composition in litchi plantation with organic mulching and its effect on litchi downy blight was limited.

In the present study, one field trail was performed to investigate the litchi downy blight under different management methods. Additionally, based on 454-pyrosequencing of the fungal internal transcribed spacer (ITS) region and the bacterial 16S rRNA gene, a comparative microbiome analysis of soils was investigated in the same litchi plantation treated with/without organic mulching. Moreover, the relationship between soil bacterial, fungal community structure and disease-suppression were discussed. This study not only explore the efficacy of organic mulching on the control of litchi downy blight, but also provided theoretical support for the application of organic mulching in litchi plantation.

\section{Materials And Methods Field experiments}

The field experiments were conducted from 2018 to 2020 at Xili Orchard in Shenzhen of China. The cultivated litchi is 'Nuomici'. The field was divided into two blocks and the treatments were: (1) the control group (CK): bare soil in conventional tillage methods, (2) the mulching group ( $\mathrm{T})$ : soil covered with litchi shredded branches and in 8-10 cm depth. To discover disease incidence and shifts in the soil microbiome, same conventional cultivation was carried out in the control group and mulching group.

\section{Disease incidence discovery}

In 2018 and 2020, disease incidence was investigated by calculating the disease incidence of dropped fruits and the litchi fruit on trees. During April and May of 2018, dropped fruits in the control field and mulching field were collected and put into plastic boxes to keep humidity. After 2-3 $d$, fruitlets covered with white mold were counted and the disease incidences were examined. Each treatment was conducted by collecting fruits from 5 different trees for one repeat, and at least 200 fruits for one repeat was calculated. In June 2020, 15 trees in the control group and mulching group were randomly selected and each repeat contained 5 trees. Disease incidence of the trees were determined by calculating 30 fruits in each of the four directions (east, south, west and north) of each tree, and diseased fruit with downy white sporangiophores were counted.

\section{Soil sampling collection}


For each treatment, 4 different soil samples from different trees were collected. The soils from $15 \mathrm{~cm}$ depth were sterile plastic bags and transported to the laboratory in an icebox immediately. The samples were stored at $-80^{\circ} \mathrm{C}$ until high-throughput sequencing and analysis.

\section{DNA extraction}

Aliquots $(0.25 \mathrm{~g})$ of the soil samples were processed using a MOBIO PowerSoil@ kit. The extracted DNA samples were analyzed using a NanoDrop 2000 UV-Vis spectrophotometer (Thermo Scientific, Wilmington, DE, USA). The DNA quality was confirmed by $1 \%$ agarose gel electrophoresis. The extracted DNA samples were selected and used to conduct microbial community analysis by PCR using primers 338F (5'-ACTCCTACGGGAGGCAGCAG-3') and 806R (5'-GGACTACHVGGGTWT CTAAT-3') for 16S rDNA in bacteria, and primers ITS1F (5'-CTTGGTCATTTAGAGGAAGTAA-3') and ITS2R (5'-

GCTGCGTTCTTCATCGATGC-3') for ITS in fungi. The PCR reactions were performed in triplicate, using 20 $\mu \mathrm{L}$ mixtures containing $4 \mu \mathrm{L} 5 \times$ FastPfu buffer, $2 \mu \mathrm{L} 2.5 \mathrm{mM}$ dNTPs, $1 \mu \mathrm{L}$ primer mix $(5 \mu \mathrm{L}), 0.4 \mu \mathrm{L}$ FastPfu polymerase, and $5 \mathrm{ng}$ extracted DNA as the template. The PCR products were extracted from a $2 \%$ agarose gel and further purified using the AxyPrep DNA Gel Extraction Kit (Axygen Biosciences, Union City, CA, USA). The products were quantified using QuantiFluor-ST (Promega, Madison, USA). Purified amplicons were then pooled in equimolar concentrations and paired-end sequenced $(2 \times 300)$ using the Illumina MiSeq platform (Illumina, San Diego, CA, USA) according to the standard protocols of Shanghai Majorbio Bio-pharm Technology Co., Ltd. Raw sequences were filtrated using FASTX Toolkit 0.0.12 software to remove low quality reads with $Q$ value $<20$ and less than $35 \mathrm{bp}$.

\section{Illumina sequencing and processing of sequencing data}

The purified amplicons were pooled on the Illumina MiSeq platform (Illumina, San Diego, USA) of equal molecular weight and paired-end sequencing $(2 \times 300)$ according to the standard protocol of MajorbioBio-Pharm Technology Co. Ltd. (Shanghai, China). The original sequencing sequence was controlled using Trimmomatic software and merged by FLASH software. The specific criteria are consistent with previous study [19]. UPARSE (version 7.1; http://drive5.com/uparse/) was used to cut the similarity of the operational classification units (OTUs) to $97 \%$. http://drive5.com/uparse/) uses a novel "greedy" algorithm that could perform chimera filtering and OTU clustering at the same time. Using the confidence threshold of $70 \%$, the classification of each 16S rRNA gene sequence was analyzed against the Silva database (Release132; http://www.arb-silva.de) through the RDP classifier algorithm (http://rdp.cme.msu.edu/). Using the confidence threshold of $70 \%$, the classification of each ITS sequence was analyzed against the Unite database (version 7.2; http: //unite.ut.ee/index.php) through the RDP classifier algorithm.

\section{Selection and identification of biocontrol bacteria and fungi}

Soils from litchi plantation treated with organic mulching for 2 years or without organic mulching were collected and used for bacteria and fungi isolation. Serial dilution method was used to isolate bacteria by dissolving soil samples $(25 \mathrm{~g})$ with sterile water $(100 \mathrm{~mL})$ in a $250 \mathrm{~mL}$ sterilized conical flask and shaking for 30 min using a rotary shaker at $150 \mathrm{rpm}$, then the resulting solutions were serially diluted up to $10^{-3}$, 
spread on LB plates and incubated at $30^{\circ} \mathrm{C}$ for $24 \mathrm{~h}$ for bacteria inoculation, and incubated on PDA plates for $3 \mathrm{~d}$ at $25^{\circ} \mathrm{C}$ for fungi inoculation [20]. Singal colonies were transferred to new LB plates (for bacteria) or PDA plates (for fungi) and used for antagonistic microorganism selection.

The antagonistic abilities of tested bacteria isolates were determined by primary and second screening as shown in Fig. 6A, and the potential antagonistic activity of fungi isolates were measured as shown in Fig. 7A. After incubating on PDA plates for $6 \mathrm{~d}$, the diameters of the pathogen zone of mycelium growth inhibition around bacteria were measured and recorded.

Then, the bacteria or fungi with markedly inhibitory activity were selected and identified by amplifying $16 \mathrm{~S}$ rRNA gene sequence of tested bacteria using universal primers $27 \mathrm{~F}$ and $1492 \mathrm{R}$, and amplifying internal transcribed spacer (ITS) of tested fungi using universal primers ITS1 and ITS4 [21, 22]. The obtained PCR products were sequenced and the sequences were subjected to Basic Local Alignment Search Tool (BLAST) searches using the National Center for Biotechnology Information (NCBI) database (http://www.ncbi.nlm.nih.gov) to compare with other sequences deposited in GenBank.

\section{Results}

\section{Organic mulching could suppress litchi downy blight}

To explore the effect of organic mulching on the inhibition of litchi downy blight, disease incidence of litchi planation under organic mulching or conventional tillage methods were investigated. The results showed a significant decrease in the disease incidence of litchi downy blight after the application of organic mulching (Fig. 1). In the investigation on April and May of 2018, the disease incidence of dropped fruits was significantly lower in mulching group than that of in control group (CK), which presented the reducing value of $7.19 \%$ and $8.70 \%$, respectively. For the disease investigation on the fruit on the tree, the disease incidence in the control field $(3.61 \%)$ was significantly higher than that in the organic mulching field $(1.51 \%)$. Our results inferred that organic mulching could delayed the development of litchi downy blight, which maybe attributed the modification of soil microbial community.

\section{Changes in the diversity of soil bacterial and fungal community}

In order to determine the response of soil microorganism to organic mulching, the bacterial and fungal diversity of soil samples treated with/without organic mulching were assessed using phylotype taxonomy. A total of 627,647 high-quality reads of bacteria and 740,047 high-quality reads of fungi were remained in the dataset with the average length of $417 \mathrm{bp}$ and $244 \mathrm{bp}$, respectively. Through clustering operations, the optimized sequences were classified into operational taxonomic units (OTUs) according to their similarity. With a $3 \%$ dissimilarity threshold, the sequences were classified into 8632 and 2175 OTUs in bacterial and fungal communities using the Ribosomal Database Project (RDP) classifier. The Venn diagrams showed that mulching soils under different period (T1, T2 and T3) exhibited a greater 
number of OTUs than control soils (CK) (Fig. 2). In bacterial communities, the numbers of OTUs in T1, T2 and T3 were more than that in CK, and that in T2 was the highest (Fig. 2A). In fungal communities, the numbers of OTUs in three mulching treatmens (T1, T2 and T3) were significantly greater than that in CK, and the highest number of fungal OTUs was 1308 which detected in T3 (Fig. 2B).

To quantify the diversity and richness of microbial community of soils among different treatments, the microbial community a-diversity were evaluated by the Ace, Chao1, Shannon and Simpson within a single microbial ecosystem, is shown in Table 1. The coverage indexes from 24 soil samples were greater than 0.97, showed that the sequencing capacity were acceptable. The richness (Ace and Chao1 indices) and diversity (Shannon and Simpson) of bacteria and fungi calculated based on the rarefied sequences showed that mulching treatment and different mulching period affected the bacterial and fungal communities. In bacterial communities, the richness (Ace and Chao1 indices) and Shannon diversity of T3 was higher than that in CK, T1 and T2 soils; while in fungal communities, the richness (Ace and Chao1 indices) of CK was higher that in mulching soils (T1, T2 and T3). However, the Simpson diversity of CK in bacterial community was slight higher than that in mulching soils ( $T 1, T 2$ and $T 3)$, while in fungal community, the Simpson diversity of CK was significantly lower than that in mulching soils ( $\mathrm{T} 1, \mathrm{~T} 2$ and T3).

Table 1

The diversity and richness indices of soil bacterial and fungal communitites

\begin{tabular}{|lllll|}
\hline & CK & T1 (1 year) & T2 (1.5 years) & T3 (2 years) \\
\hline Bacteria & & & & \\
\hline Ace & $3965.47 \pm 60.20$ & $4920.88 \pm 66.58$ & $5004.96 \pm 61.42$ & $5388.96 \pm 56.98$ \\
\hline Chao1 & $3889.78 \pm 37.22$ & $4863.81 \pm 50.06$ & $5025.71 \pm 11.38$ & $5086.18 \pm 44.44$ \\
\hline Shannon & $6.67 \pm 0.05$ & $6.98 \pm 0.03$ & $6.95 \pm 0.01$ & $7.05 \pm 0.06$ \\
\hline Simpson (\%) & $0.33 \pm 0.01$ & $0.22 \pm 0.01$ & $0.25 \pm 0.01$ & $0.22 \pm 0.01$ \\
\hline Coverage (\%) & $97.65 \pm 0.14$ & $97.12 \pm 0.11$ & $97.16 \pm 0.45$ & $97.07 \pm 0.09$ \\
\hline Fungi & & & & \\
\hline Ace & $983.32 \pm 19.59$ & $764.41 \pm 33.17$ & $732.07 \pm 35.70$ & $888.89 \pm 9.81$ \\
\hline Chao1 & $989.24 \pm 17.79$ & $778.13 \pm 51.10$ & $748.22 \pm 38.41$ & $886.31 \pm 10.85$ \\
\hline Shannon & $4.63 \pm 0.16$ & $3.25 \pm 0.39$ & $4.11 \pm 0.20$ & $3.97 \pm 0.24$ \\
\hline Simpson (\%) & $2.42 \pm 0.51$ & $16.49 \pm 2.09$ & $4.67 \pm 0.76$ & $5.47 \pm 0.30$ \\
\hline Coverage (\%) & $99.81 \pm 0.03$ & $99.69 \pm 0.02$ & $99.81 \pm 0.06$ & $99.77 \pm 0.04$ \\
\hline
\end{tabular}

To get a better insight into the differences of the soil microbial communities, the principal coordinates analysis (PCOA) based on the Bray-Curtis distance was applied to evaluate the microbial community $\beta$ - 
diversity. As shown in Fig. 3A, samples of CK and T3 were distributed separately at $52.63 \%$ and $15.57 \%$ on the pCoA vector $x$ and $y$ axes for the bacterial community, while T2 and T3 were contiguous but distinct from CK and T3. Likewise, the pCoA variation (39.61\% for PC1 and 19.44\% for PC2) accounted for the fungal community across all samples (Fig. 3B). All soil samples distinct from the others expect for $\mathrm{T} 1$ and $\mathrm{T} 2$, demonstrated that large microbial community differences affected by organic mulching and different mulching period.

\section{Bacterial communities in the Soil}

Obvious differences in the composition and diversity of the bacterial communities were found across the soil. As shown in Fig. 4A, Proteobacteria, Actinobacteria, Acidobacteria and Chloroflexi, in rank order, were the abundant phyla in both treatments, and Proteobacteria, Acidobacteria and Bacteroidota in mulching soils(T1, T2 and T3) were significantly larger than in control soil (CK). At the genus level, relative abundance of top 10 bacterial communities was identified, and top 3 microbial communities (norank_f_norank_o_Vicinamibacterales, Norank_f_Vicinamibacterace -ae, Norank_f_Xanthobacteraceae) significantly increased in response to organic mulching (Fig. 4B).

\section{Fungal communities in the Soil}

To dissect the taxonomic composition of fungal communities in the soil, relative abundance of the dominant fungal communities at phylum and genus levels were aligned. At the phylum level, Ascomycota was significantly dominated across both treatments, and its relative abundance in T2 and T3 treatment significantly higher compared to control soil (CK) (Fig. 5A). Notably, organic mulching markely increased the relative abundance of Thermomyces, Aspergillus and Acremonium in the soil, whereas, the relative abundance of Neocosmospora in fungal community were significantly decreased with the increasing period of mulching treatment (Fig. 5B).

\section{Identification of antagonistic bacteria contributing to antimicrobial activity}

The richness and species of antagonistic bacteria were positively associated with the survival of pathogen. From the primary and second screening, a total of 50 antagonistic bacteria strains were obtained, with 18 strains were common in both treatments, and 29 and 3 strains were unique for mulching soils and control soils (CK), respectively (Fig. 6B). Based on the sequence similarities to the $16 \mathrm{~S}$ rRNA gene sequences, 8 different species of antagonistic bacteria with excellent antimicrobial efficacy were identified. These were Burkholderia gladioli, Leuconostoc mesenteroides, Paenibacillus polymyxa, Bacillus subtilis, B. altitudinis, B. velezensis, B. amyloliquefaciens, and B. vallismortis (Fig. 6C).

\section{Identification of antagonistic fungi contributing to antimicrobial activity}


To evaluate the antimicrobial activity of enrichment fungal cultures against $P$. litchii, primary and second screening test were conducted. In total, 52 antagonistic fungal strains were obtained, with 13 strains were common in both treatments, and 37 and 2 strains were unique for mulching soils and control soils (CK), respectively (Fig. 7B). As a result of ITS sequences alignment, eight major species of antagonistic fungi with excellent antimicrobial efficacy were identified from organic mulching soils, which belonging to Trichoderma sp. and Penicillium sp. (Fig. 7C).

\section{Discussion}

Organic mulching was widely adopted in agricultural cultivation for a long time. The general effect of mulching on soils has also been fully recognized [23]. However, in terms of the influence of organic mulching on the control of disease and the composition of microorganisms in soils, the depth of understanding is far from enough [6].

The results of the present study indicated that organic mulching application led to a significant decline in the disease incidence of litchi downy blight, along with an increase in the abundance of soil bacterial and fungal community. The findings were in line with numerous studies on other crops that practices of bioorganic fertilizer application raised soil microbial diversity and enhance plant disease suppression [24, 25]. Therefore, the modification of soil microbial community composition and functional potentials might contribute to the increase of disease suppression on litchi downy blight under organic mulching application.

The structure and functions of soil microbial community are closely related to soil quality and ecosystem stability and sustainability, which are crucial for plant health and productivity [26]. Various studies demonstrated the alteration of soil microbial community was closely associated with soil suppressiveness to soilborne pathogenic fungi $[27,28]$. Wu et al. highlighted the close association between replant disease and the variations in structure and potential functions of rhizosphere bacterial community [29]. Yang et al. indicated that soil microbial diversity had a strong effect on tobacco wilt disease level [30]. In addition, any modifications in soil microbial community assemblages will have a cascade of effects on soil structure and nutrient cycling, including soil aggregate stability and decomposition processes [31, 32].

Soil microbiota is considered to be a critical factor to regulate soil quality and sustainability [33], its community and diversity are significant involved with soil-plant health via triggering different functional roles, which including decomposing organic matter, ecosystem regulators, and biological antagonism [34, 35]. In this study, we found that organic mulching application could increase the soil bacterial community diversity and enhance the populations of beneficial microorganisms. Similarly, the phyla Proteobacteria, Actinobacteria, Acidobacteria and Chloroflexi, which are consistently predominant bacteria in tillage soil [36], are dominant bacteria in our study. Proteobacteria plays an important role in straw decomposition and soil nutrient uptake [37], and Acidobacteria is considered to have extensive metabolic and genetic functions [38]. Therefore, the relative abundance of phyla Proteobacteria and Acidobacteria increased 
after organic mulching application might be attribute to organic matter incorporation. The fungal taxonomic composition and richness of functional fungi in the soils under organic mulching methods also significantly higher than that in bare soils with conventional tillage methods. The dominant Aspergillus and Thermomyces genera were observed under organic mulching application. Certain affiliated genera including Thermomyces spp. are the key contributors to the hemicellulose hydrolysis during root-surrounding decomposition, which supply nutrients to microbial system in the soils [39].

Litchi downy blight caused by $P$. litchii is one of the most destructive diseases in litchi planation. As the important origin of primary infection, residual pathogens on dropped-blossoms and fruits play crucial role in epidemic of litchi downy blight [40]. Our findings indicated that organic mulching application reduced disease incidence and manipulated the soil microbial community structure, especially the increasing bacterial families such as Burkholderia, Bacillus, and Paenibacillus, which have been proved to possess antagonistic activities and contribute to disease suppressiveness [41-43]. Moreover, the frequent occurrence of specific beneficial fungal species, such as Trichoderma sp. and Penicillium sp., reflect the survival of $P$. litchii in planting system. Several studies revealed the excellent beneficial effects of Trichoderma, Aspergillus and Penicillium for pathogen control [44-47]. Their fungal abundance may be also related to the suppression of litchi downy blight through mycoparasitism fabrication of lytic enzymes and antimicrobial chemicals and competing for space and food, which was consistent with mentioned results of the reduction of litchi downy blight in organic mulching soils. On the other hand, organic mulching application led to a significant decrease in the relative abundance of the genus Fusarium, which is the major crop pathogens in the world and attribute to many soilborne disease through colonizing root surfaces, producing some plant irritant and some secondary metabolite during growth and metabolism [48], exhibited lower abundance in organic mulching soils in comparison with control soils. Therefore, organic mulching might have exerted positive feedback effects on litchi planation and resistance through inhibiting potential soil borne pathogens and fostering plant-beneficial microbes which targeting the causal agent $P$. litchii.

In conclusion, the findings in this study revealed that the litchi downy blight was closely associated with dysbiosis of soil microbiota. The organic mulching application could delay this disease mainly depend on reshaping the soil microbial community and modifying the potential functions microbes that harbor antagonistic activities against $P$. litchii and contribute to soil suppressiveness. Our results reinforce the influence of organic mulching on disease control and soil microbial diversity in litchi plantation from the aspects of microbial structure and ecological function. Further work is needed to investigate the survival of causal agent in the presence of beneficial microorganisms and to link the potential functions to organic mulching application.

\section{Conclusions}

Organic mulching is capable of modifying soil microbial community by contributing to higher bacterial and fungal community diversity, and lower the abundances of plant-harmful microbes which potential as plant pathogens, thus improved soil-plant growth productivity. Moreover, litchi downy blight was highly 
delayed after the application of organic mulching, which attributed to the improvement of abundances of plant-beneficial microbes that significantly contributed to antagonizing Peronophythora litchii. Our work further demonstrated the structural alteration of soil bacterial and fungal communities and thus explained the positive correlation with suppression of litchi downy blight in response to organic mulching, providing a suitable method for litchi plantation.

\section{Declarations}

\section{Declarations}

Funding This research was funded by Key-Area Research and Development Program of Guangdong Province (2018B020205003), earmarked grants for China agriculture research system (CARS-32), Postdoctoral Foundation Project of Shenzhen Polytechnic (6019330008K).

Conflicts of Interest The authors declare no conflict of interest.

Data AvailabilityNot applicable.

Code AvailabilityNot applicable.

Author Contributions: Conceptualization, X.D., L.J., P.A., and Q.F.; Methodology and Investigation, X.D., L.J., X.P. and Z.Y.; Software, L.C.; Validation, Q.F., Z.J., and J.Z.; Writing - Review \& Editing, X.D., P.A., Q.F., and J.Z.; Funding Acquisition, Q.F. and J.Z. All authors have read and agreed to the published version of the manuscript.

Ethics Approval Not applicable.

Consent to Participate Not applicable.

Consent for Publication Not applicable.

Acknowledgements We thanks Weiyi Zheng, Yanmin Shen and Jingyi Li for assisting us with laboratory procedures and field survey.

\section{References}

\section{References}

1. Jiménez MN, Pinto JR, Ripoll MA, Sánchez-Miranda A, Navarro FB (2017) Impact of straw and rockfragment mulches on soil moisture and early growth of holm oaks in a semiarid area. Catena 152:198-206. https://doi.org/10.1016/j.catena.2017.01.021

2. Forge TA, Hogue E, Neilsen G, Neilsen D (2003) Effects of organic mulches on soil microfauna in the root zone of apple: implications for nutrient fluxes and functional diversity of the soil food web. Appl Soil Ecol 22:39-54. https://doi.org/10.1016/S0929-1393(02)00111-7 
3. Thankamani CK, Kandiannan K, Hamza S, Saji KV (2016) Effect of mulches on weed suppression and yield of ginger (Zingiber officinale Roscoe). Sci Hortic 207:125-130. https://doi.org/10.1016/j.scienta.2016.05.010

4. Renkema JM, Cutler GC, Lynch DH, Mackenzie K, Walde SJ (2016) Organic mulches in highbush blueberries alter beetle (Coleoptera) community composition and improve functional group abundance and diversity. Agric Forest Entomol 18:119-127. https://doi.org/10.1111/afe.12144

5. Ramírez-Gil JG, Castañeda-Sánchez DA, Morales-Osorio JG (2017) Production of avocado trees infected with Phytophthora cinnamomi under different management regimes. Plant Pathol 66:623632. https://doi.org/10.1111/ppa.12620

6. Yang Y, Dungan RS, Ibekwe AM, Valenzuela-Solano C, Crohn DM, Crowley DE (2003) Effect of organic mulches on soil bacterial communities one year after application. Biol Fert Soils 38:273-281. https://doi.org/10.1007/s00374-003-0639-9

7. Mori AS, Isbell F, Seidl R (2018) $\beta$-Diversity, community assembly, and ecosystem functioning. Trends Ecol Evol 33:549-564. https://doi.org/10.1016/j.tree.2018.04.012

8. Chaparro JM, Sheflin AM, Manter DK, Vivanco JM (2012) Manipulating the soil microbiome to increase soil health and plant fertility. Biol Fert Soils 48:489-499. https://doi.org/10.1007/s00374012-0691-4

9. Lan G, Li Y, Wu Z, Xie G (2017) Soil bacterial diversity impacted by conversion of secondary forest to rubber or eucalyptus plantations: a case study of Hainan Island, South China. Forest Sci 63:87-93. https://doi.org/10.5849/forsci.16-012

10. Zhang S, Wang Y, Sun L, Qiu C, Ding Y, Gu H, Wang L, Wang Z, Ding Z (2020) Organic mulching positively regulates the soil microbial communities and ecosystem functions in tea plantation. Bmc Microbiol 20:103. https://doi.org/10.1186/s12866-020-01794-8

11. Brennan EB, Acosta-Martinez V (2017) Cover cropping frequency is the main driver of soil microbial changes during six years of organic vegetable production. Soil Biol Biochem 109:188-204. https://doi.org/10.1016/j.soilbio.2017.01.014

12. Berg G, Rybakova D, Grube M, Köberl M (2016) The plant microbiome explored: implications for experimental botany. J Exp Bot 67:995-1002. https://doi.org/10.1093/jxb/erv466

13. Berendsen RL, Pieterse CMJ, Bakker PAHM (2012) The rhizosphere microbiome and plant health. Trends Plant Sci 17:478-486. https://doi.org/10.1016/j.tplants.2012.04.001

14. Zhang Y, Hu A, Zhou J, Zhang W, Li P (2020) Comparison of bacterial communities in soil samples with and without tomato bacterial wilt caused by Ralstonia solanacearum species complex. Bmc Microbiol 20:89. https://doi.org/10.1186/s12866-020-01774-y

15. Kwak M, Kong HG, Choi K, Kwon S, Song JY, Lee J, Lee PA, Choi SY, Seo M, Lee HJ, Jung EJ, Park H, Roy N, Kim H, Lee MM, Rubin EM, Lee S, Kim JF (2018) Rhizosphere microbiome structure alters to enable wilt resistance in tomato. Nat Bitechnol 36:1100. https://doi.org/10.1038/nbt.4232

16. Ann PJ, Ko WH (1984) Blossom blight of litchi in Taiwan caused by Peronophythora litchii. Plant Dis $68: 826$ 
17. Xu D, Deng Y, Xi P, Zhu Z, Kong X, Wan L, Situ J, Li M, Gao L, Jiang Z (2018) Biological activity of pterostilbene against Peronophythora litchii, the litchi downy blight pathogen. Postharvest Biol Technol 144:29-35. https://doi.org/10.1016/j.postharvbio.2018.05.011

18. Zhang J, Zhou Q, Gong X, Zeng Y, Qiao F, Peng G (2020) Effects of shredding branches cover on the physicochemical proerties and fertility of soil in lychee orchard. J Anhui Agric Sci 48:159-161

19. Ye X, Li Z, Luo X, Wang W, Li Y, Li R, Zhang B, Qiao Y, Zhou J, Fan J, Wang H, Huang Y, Cao H, Cui Z, Zhang R (2020) A predatory myxobacterium controls cucumber Fusarium wilt by regulating the soil microbial community. Microbiome 8:49. https://doi.org/10.1186/s40168-020-00824-x

20. Wang X, Li Q, Sui J, Zhang J, Liu Z, Du J, Xu R, Zhou Y, Liu X (2019) Isolation and characterization of antagonistic bacteria Paenibacillus jamilae HS-26 and their effects on plant growth. Biomed Res Int 2019:3638926. https://doi.org/10.1155/2019/3638926

21. Weisburg WG, Barns SM, Pelletier DA, Lane DJ (1991) 16S ribosomal DNA amplification for phylogenetic study. J Bacteriol 173:697-703. https://doi.org/10.1128/jb.173.2.697-703.1991

22. White TJ, Bruns T, Lee S, Taylor J (1990) Amplification and direct sequencing of fungal ribosomal RNA genes for phylogenetics. In: Innis MA, Gelfand DH, Sninsky JJ, White TJ (eds) PCR Protocols: A guide to methods and applications. edn. Academic Press, San Diego, pp 315-322

23. Jabran K (2019) Mulches for soil and water conservation. In: Jabran K (ed) Role of mulching in pest management and agricultural sustainability, 1nd edn. Springer International Publishing, Cham, pp 33-39

24. Tao C, Li R, Xiong W, Shen Z, Liu S, Wang B, Ruan Y, Geisen S, Shen Q, Kowalchuk GA (2020) Bioorganic fertilizers stimulate indigenous soil Pseudomonas populations to enhance plant disease suppression. Microbiome 8:137. https://doi.org/10.1186/s40168-020-00892-z

25. Zhao J, Wang Y, Liang H, Huang J, Chen Z, Nie Y (2018) The rhizosphere microbial community response to a bio-organic fertilizer: finding the mechanisms behind the suppression of watermelon Fusarium wilt disease. Acta Physiol Plant 40:17. https://doi.org/10.1007/s11738-017-2581-8

26. Tang X, Zou L, Su S, Lu Y, Zhai W, Manzoor M, Liao Y, Nie J, Shi J, Ma LQ, Xu J (2021) Long-term manure application changes bacterial communities in rice rhizosphere and arsenic speciation in rice grains. Environ Sci Technol 55:1555-1565. https://doi.org/10.1021/acs.est.0c03924

27. Wang L, Li X (2019) Steering soil microbiome to enhance soil system resilience. Crit Rev Microbiol 45:743-753. https://doi.org/10.1080/1040841X.2019.1700906

28. Wang L, Li J, Yang F, E Y, Raza W, Huang Q, Shen Q (2017) Application of bioorganic fertilizer significantly increased apple yields and shaped bacterial community structure in orchard soil. Microb Ecol 73:404-416. https://doi.org/10.1007/s00248-016-0849-y

29. Wu L, Yang B, Li M, Chen J, Xiao Z, Wu H, Tong Q, Luo X, Lin W (2020) Modification of rhizosphere bacterial community structure and functional potentials to control Pseudostellaria heterophylla replant disease. Plant Dis 104:25-34. https://doi.org/10.1094/PDIS-04-19-0833-RE

30. Yang H, Li J, Xiao Y, Gu Y, Liu H, Liang Y, Liu X, Hu J, Meng D, Yin H (2017) An integrated insight into the relationship between soil microbial community and tobacco bacterial wilt disease. Front 
Microbiol 8:2179. https://doi.org/10.3389/fmicb.2017.02179

31. Merino-Martín L, Griffiths RI, Gweon HS, Furget-Bretagnon C, Oliver A, Mao Z, Le Bissonnais Y, Stokes A (2020) Rhizosphere bacteria are more strongly related to plant root traits than fungi in temperate montane forests: insights from closed and open forest patches along an elevational gradient. Plant Soil 450:183-200. https://doi.org/10.1007/s11104-020-04479-3

32. Das S, Hwang HY, Song HJ, Cho SR, Van Nostrand JD, Kim PJ (2021) Soil microbial response to silicate fertilization reduces bioavailable arsenic in contaminated paddies. Soil Biol Biochem 159:108307. https://doi.org/10.1016/j.soilbio.2021.108307

33. Mi Y, Zhao X, Liu F, Sun C, Sun Z, Liu L (2021) Changes in soil quality, bacterial community and antipepper Phytophthora disease ability after combined application of straw and multifunctional composite bacterial strains. Eur J Soil Biol 105:103329. https://doi.org/10.1016/j.ejsobi.2021.103329

34. Ali A, Imran Ghani M, Li Y, Ding H, Meng H, Cheng Z (2019) Hiseq base molecular characterization of soil microbial community, diversity structure, and predictive functional profiling in continuous cucumber planted soil affected by diverse cropping systems in an intensive greenhouse region of northern China. Int J Mol Sci 20:2619. https://doi.org/10.3390/ijms20112619

35. Ali A, Ghani MI, Haiyan D, Iqbal M, Cheng Z, Cai Z (2020) Garlic substrate induces cucumber growth development and decreases fusarium wilt through regulation of soil microbial community structure and diversity in replanted disturbed soil. Int J Mol Sci 21:6008. https://doi.org/10.3390/ijms21176008

36. Li C, Yan K, Tang L, Jia Z, Li Y (2014) Change in deep soil microbial communities due to long-term fertilization. Soil Biol Biochem 75:264-272. https://doi.org/10.1016/j.soilbio.2014.04.023

37. Chaudhry V, Rehman A, Mishra A, Chauhan PS, Nautiyal CS (2012) Changes in bacterial community structure of agricultural land due to long-term organic and chemical amendments. Microb Ecol 64:450-460. https://doi.org/10.1007/s00248-012-0025-y

38. Li H, Xu Z, Yang S, Li X, Top EM, Wang R, Zhang Y, Cai J, Yao F, Han X, Jiang Y (2016) Responses of soil bacterial communities to nitrogen deposition and precipitation increment are closely linked with aboveground community variation. Microb Ecol 71:974-989. https://doi.org/10.1007/s00248-0160730-z

39. Singh S, Madlala AM, Prior BA (2003) Thermomyces lanuginosus: properties of strains and their hemicellulases. Fems Microbiol Rev 27:3-16. https://doi.org/10.1016/S0168-6445(03)00018-4

40. Zhang R, Huaqiang L, Jiang Z, Yang Y, Wan C, Chen H (2014) Effect of dropped-blossoms and fruits on primary inoculum source germination on litchi downy blight in litchi orchard. China Plant Protect 34:13-16

41. De Corato U (2020) Disease-suppressive compost enhances natural soil suppressiveness against soil-borne plant pathogens: A critical review. Rhizosphere 13:100192. https://doi.org/10.1016/j.rhisph.2020.100192 
42. Ili Nadhrah N, Nulit R, Nurrashyeda R, Idris AS (2015) Effect of formulated bioorganic containing Burkholderia GanoEB2 in suppressing Ganoderma disease in oil palm seedlings. Plant Protect Sci 51:80-87. https://doi.org/10.17221/26/2014-PPS

43. Ahmad AM, Attia AG, Mohamed MS, Elsayed HE (2019) Fermentation, formulation and evaluation of PGPR Bacillus subtilis isolate as a bioagent for reducing occurrence of peanut soil-borne diseases. J Integr Agric 18:2080-2092. https://doi.org/10.1016/S2095-3119(19)62578-5

44. Rodríguez-Andrade E, Stchigel AM, Cano-Lira JF (2021) New xerophilic species of Penicillium from soil. J Fungi 7:126. https://doi.org/10.3390/jof7020126

45. Nandini B, Puttaswamy H, Saini RK, Prakash HS, Geetha N (2021) Trichovariability in rhizosphere soil samples and their biocontrol potential against downy mildew pathogen in pearl millet. Sci Rep 11:9517. https://doi.org/10.1038/s41598-021-89061-2

46. Mukhopadhyay R, Kumar D (2020) Trichoderma: a beneficial antifungal agent and insights into its mechanism of biocontrol potential. Egypt J Biol Pest Co 30:133. https://doi.org/10.1186/s41938020-00333-x

47. El-Sayed ASA, Ali GS (2020) Aspergillus flavipes is a novel efficient biocontrol agent of Phytophthora parasitica. Biol Control 140:104072. https://doi.org/10.1016/j.biocontrol.2019.104072

48. Mangan SA, Schnitzer SA, Herre EA, Mack KML, Valencia MC, Sanchez El, Bever JD (2010) Negative plant-soil feedback predicts tree-species relative abundance in a tropical forest. Nature 466:752755. https://doi.org/10.1038/nature09273

\section{Figures}




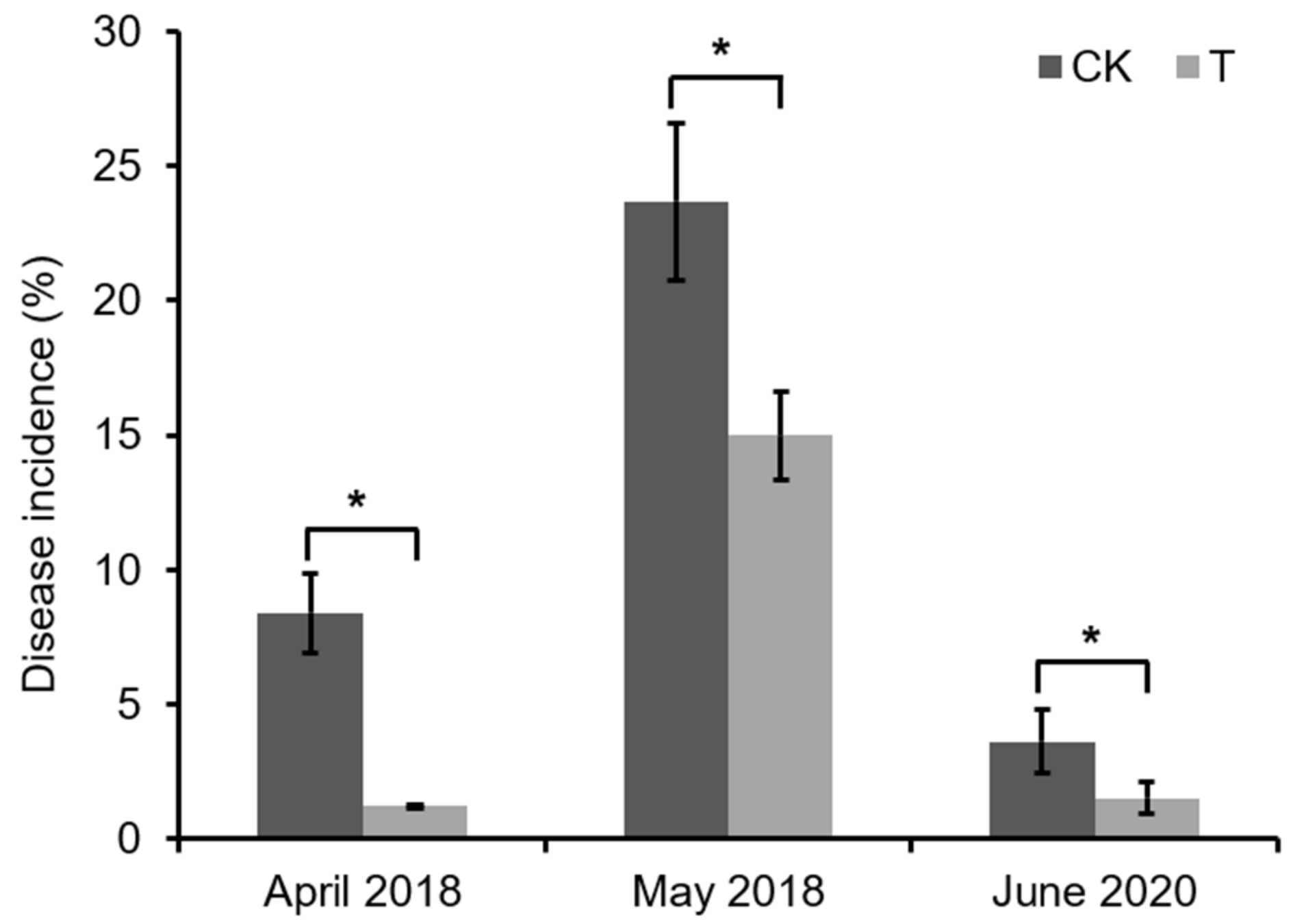

Figure 1

Disease incidence of litchi downy blight from control group (CK) and mulching group (T) in 2018 and 2020. For 2018, disease incidence of dropped fruit was investigated on April and May. For 2020, disease incidence of fruit on the tree in different group was conducted on June. Results are represented as the mean of all replicates \pm standard error (SE). The asterisks $\left(^{*}\right)$ indicate significant difference between different treatments. 

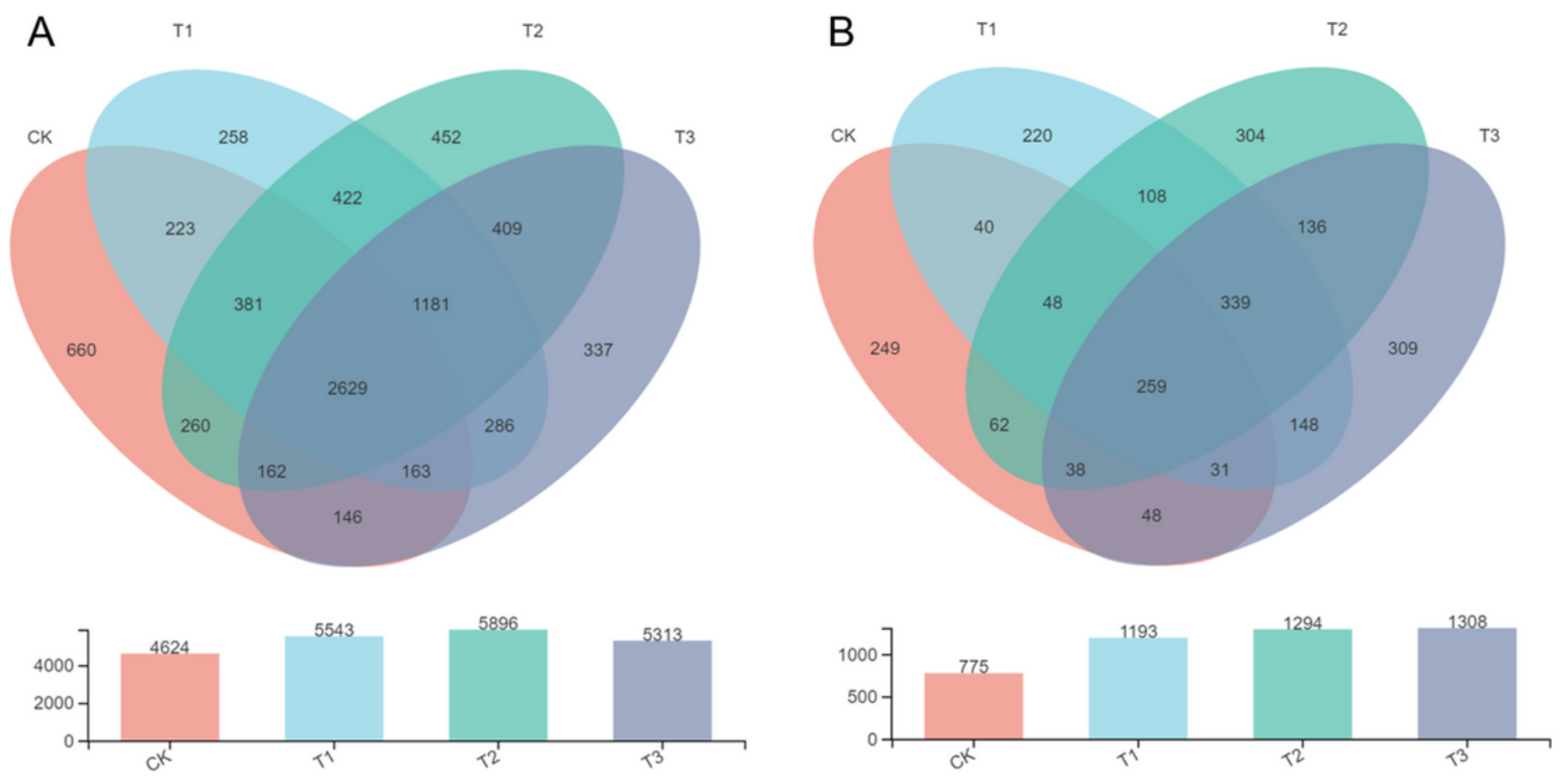

Figure 2

The Venn diagram of microbial communities in soils under different treatments. A, the number of bacterial OTUs in soils under different treatments; $B$, the number of fungal OTUs in soils under different treatments. CK, bare soil in conventional tillage methods; $\mathrm{T} 1$, treated with mulching for 1 year; $\mathrm{T} 2$, treated with mulching for 1.5 years; T3, treated with mulching for 2 years.
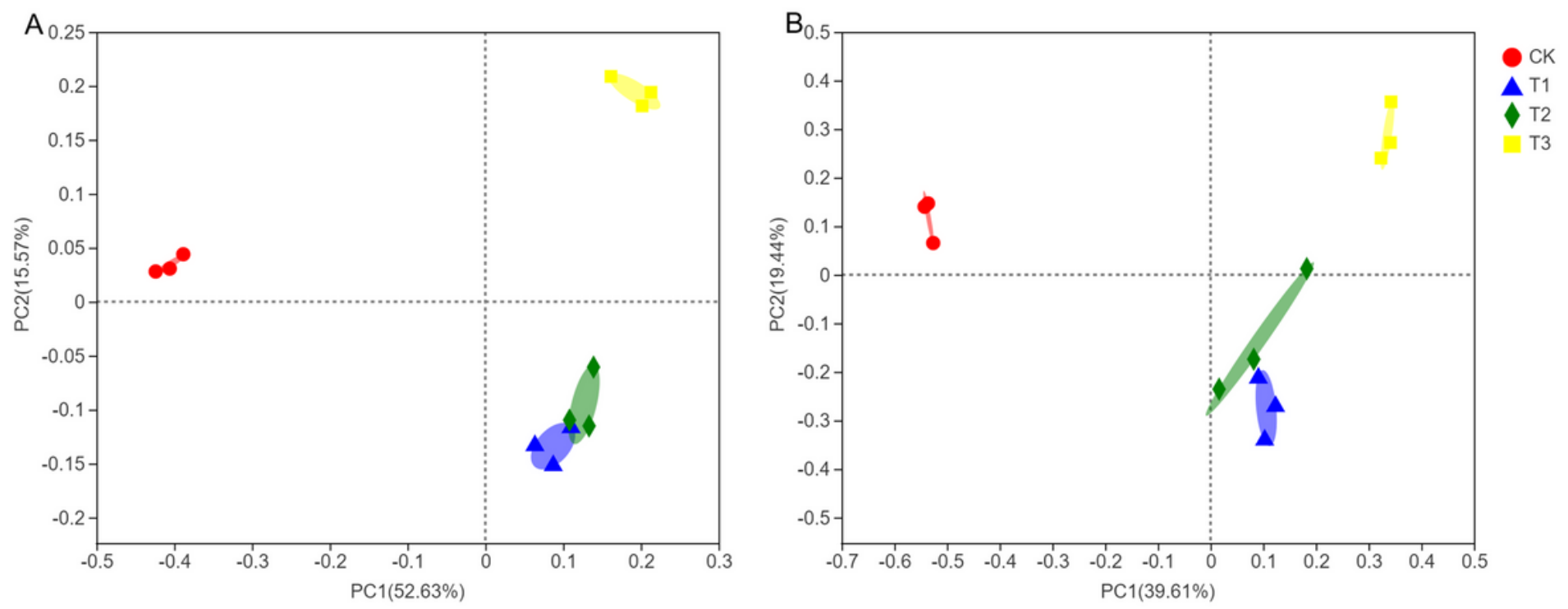

\section{Figure 3}

The principal co-ordinates analysis ( $\mathrm{pCoA}$ ) based on the Bray-Curtis distance in microbial communities in soils under different treatments. $A$, the distribution of bacterial communities in soils under different treatments; B, the distribution of fungal communities in soils under different treatments. CK, bare soil in 
conventional tillage methods; T1, treated with mulching for 1 year; T2, treated with mulching for 1.5 years; T3, treated with mulching for 2 years.
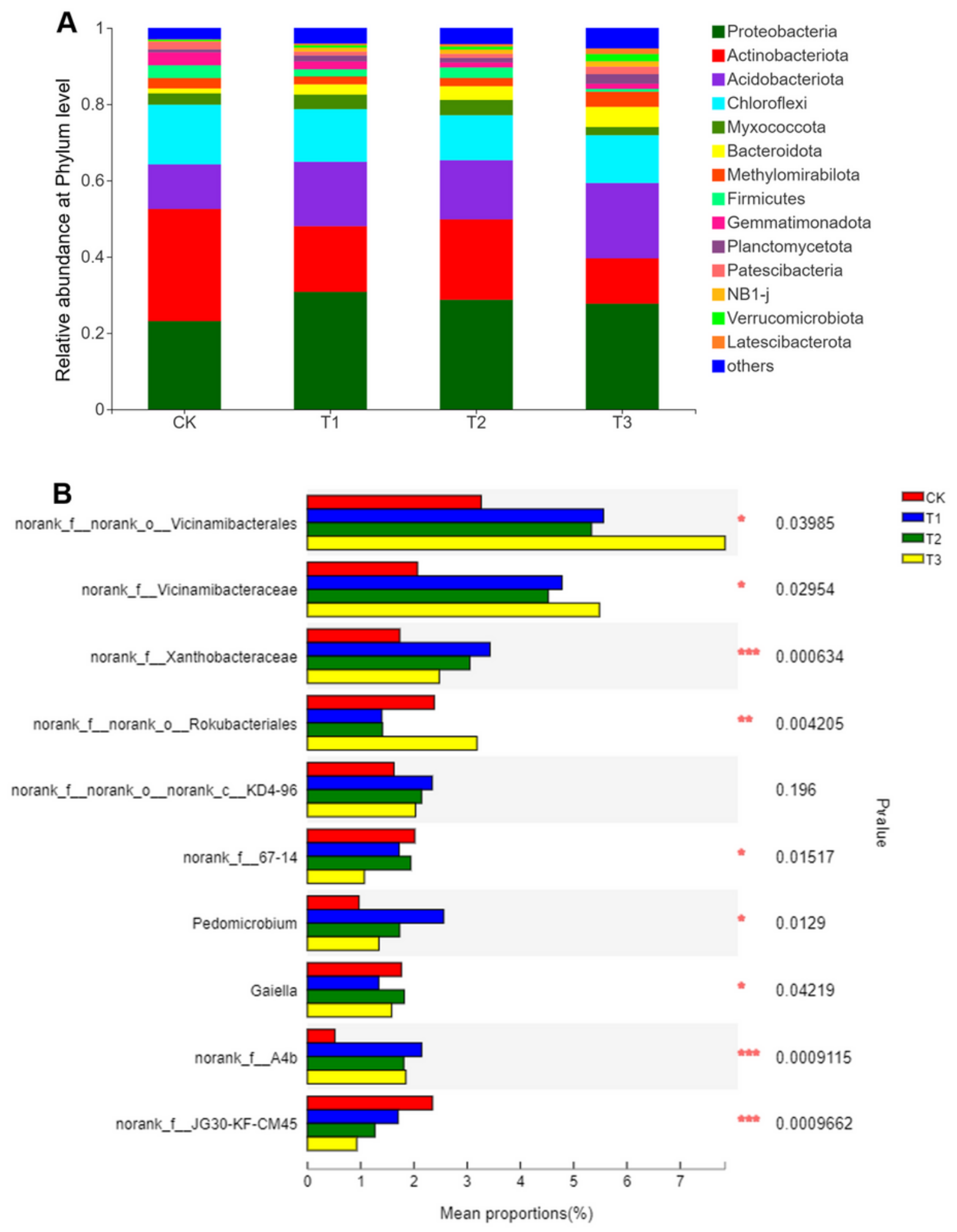

Figure 4

The relative abundance of main bacterial communities in soil under different treatments. $A$, relative abundance of the dominant bacterial community at phylum level; B, relative abundance of top 10 bacterial community at genus level. The "others" comprise the unclassified and low-abundance phyla. CK, 
bare soil in conventional tillage methods; $\mathrm{T} 1$, treated with mulching for 1 year; $\mathrm{T} 2$, treated with mulching

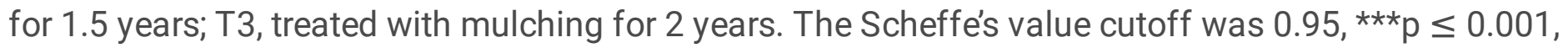
$* * 0.001<p \leq 0.01$, and $* 0.01<p \leq 0.05$.
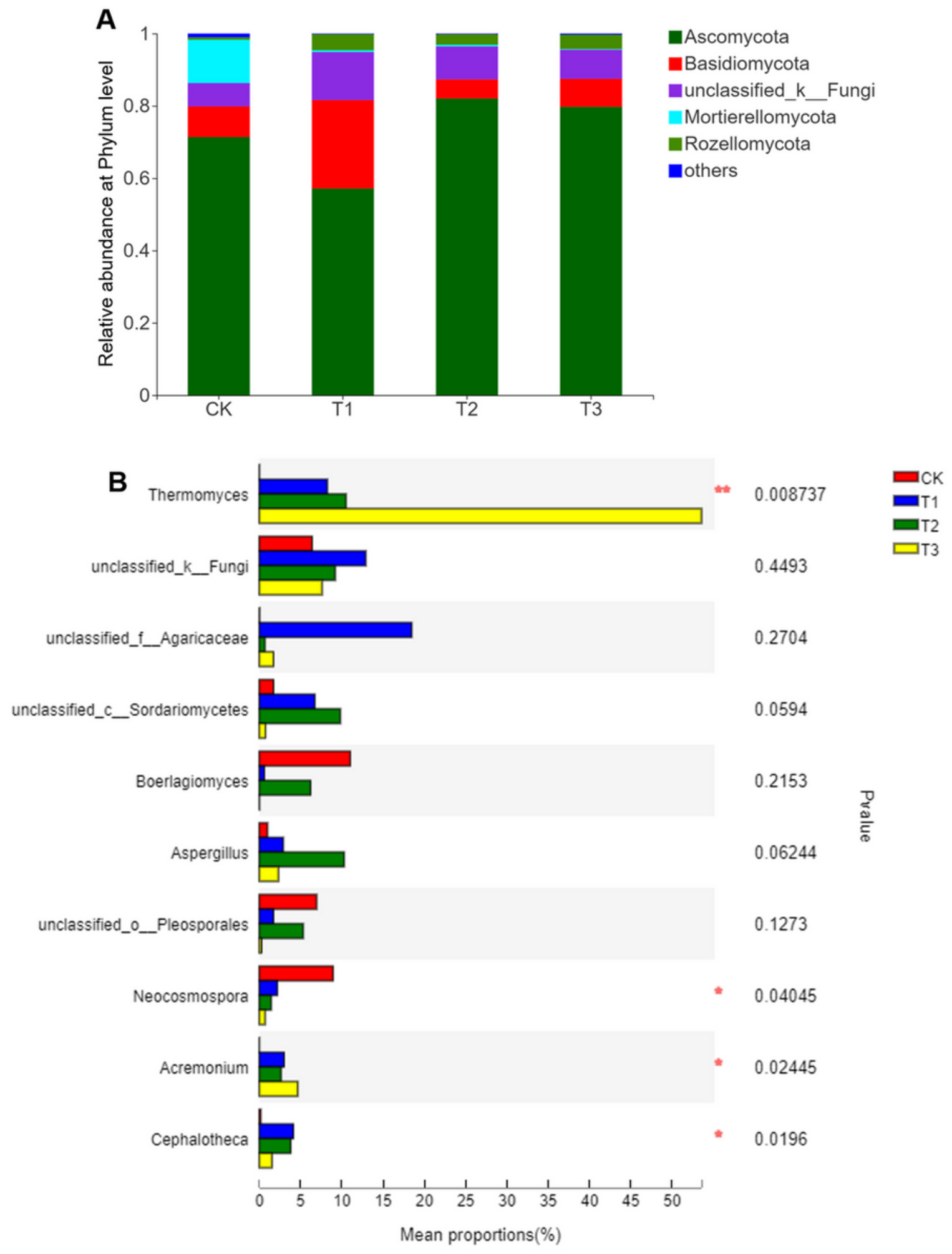

Figure 5

The relative abundance of main fungal communities in soil under different treatments. A, relative abundance of the dominant fungal community at phylum level; $B$, relative abundance of top 10 fungal 
community at genus level. The "others" comprise the unclassified and low-abundance phyla. CK, bare soil in conventional tillage methods; $\mathrm{T} 1$, treated with mulching for 1 year; T2, treated with mulching for 1.5

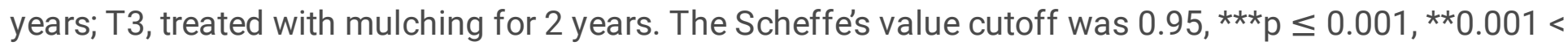
$p \leq 0.01$, and $* 0.01<p \leq 0.05$.

A Biocontrol bacteria screening

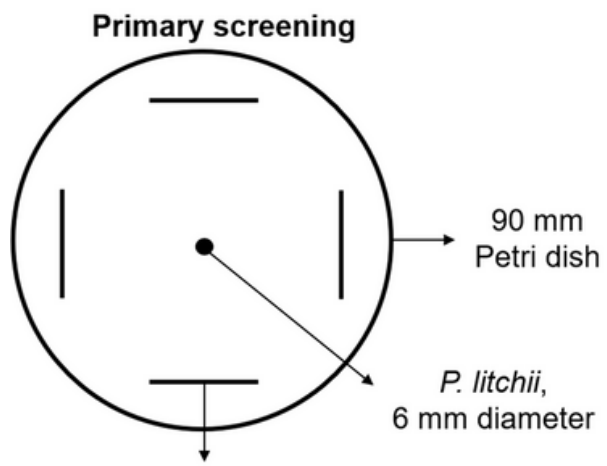

One in each direction, each of $25 \mathrm{~mm}$ length
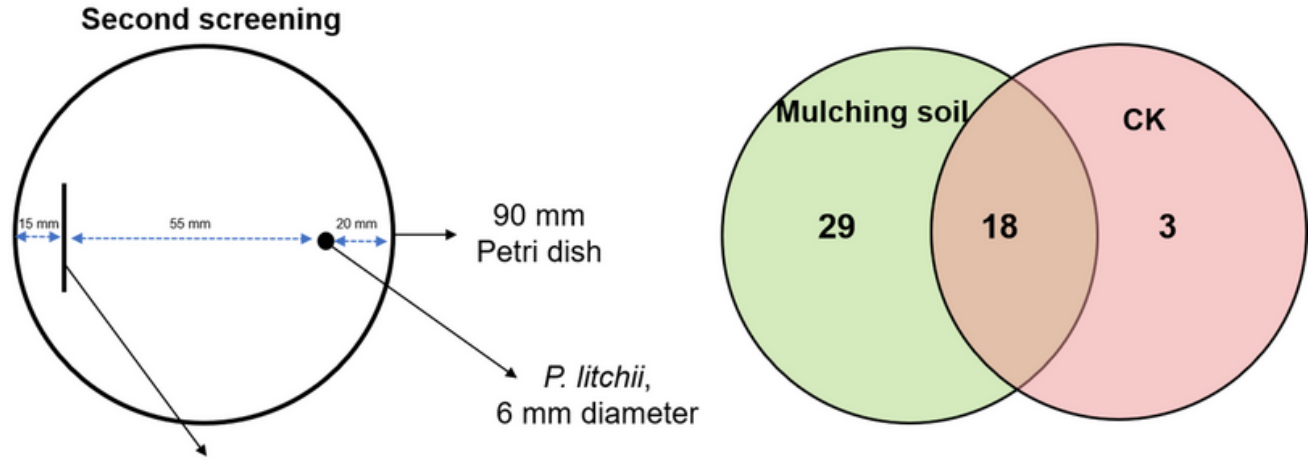

$25 \mathrm{~mm}$ length

B

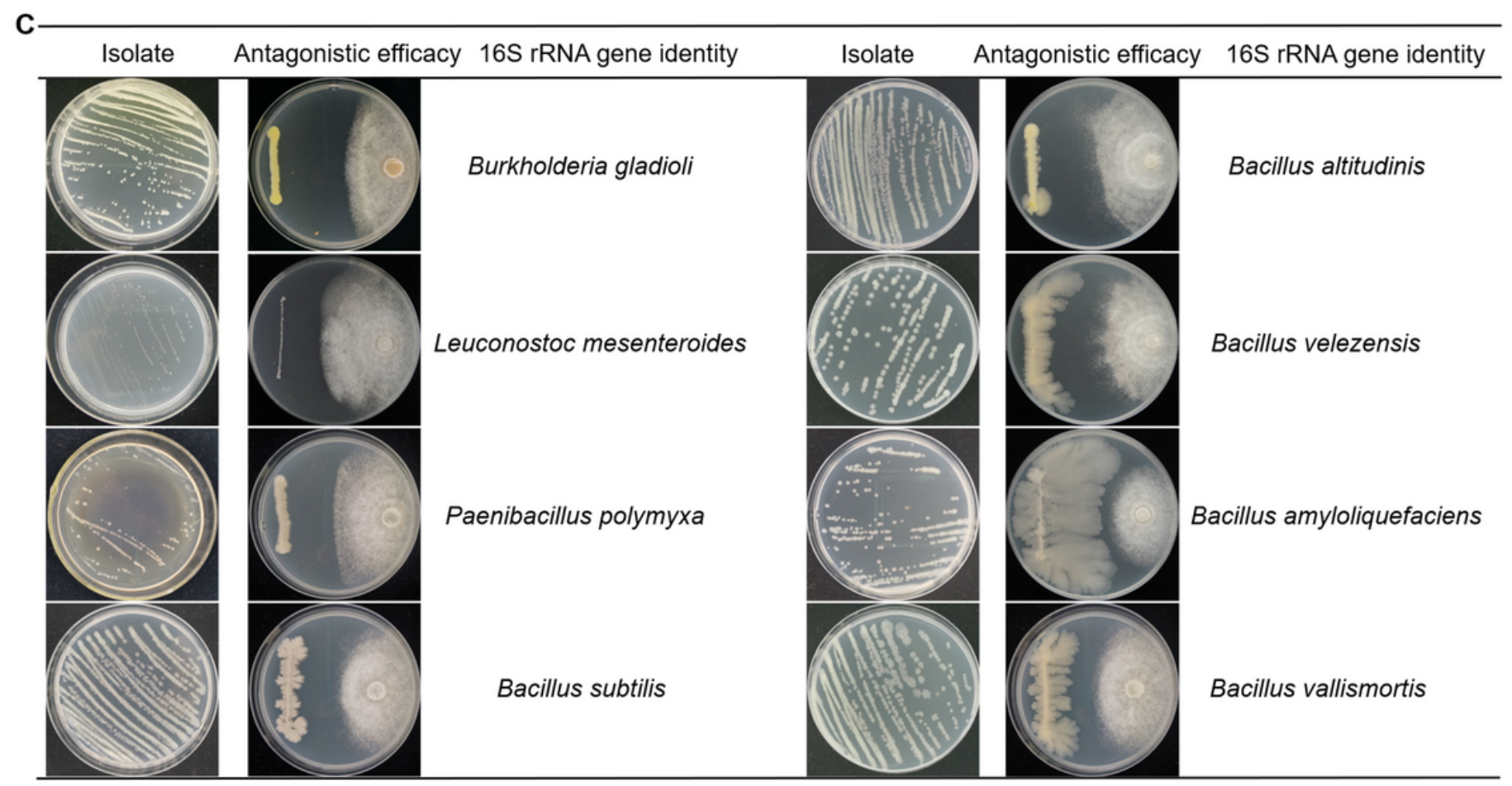

Figure 6

Screening and characterization of antagonistic bacteria isolates detected in this study. A, the method of biocontrol bacteria screening; $B$, Venn diagram for common and unique strains detected from mulching soils (mulching for 2 years) and control soils (CK, bare soil in conventional tillage methods); C, Characterization of antagonistic bacteria isolates detected in this study. 
A Biocontrol fungi screening

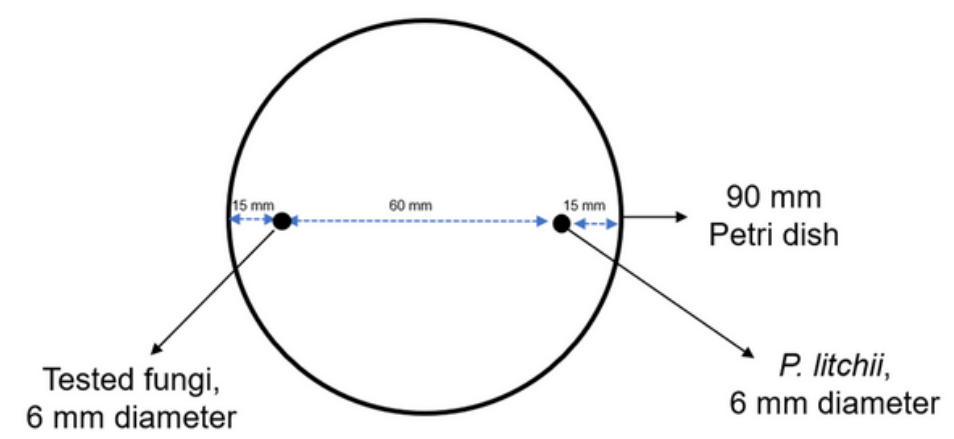

B

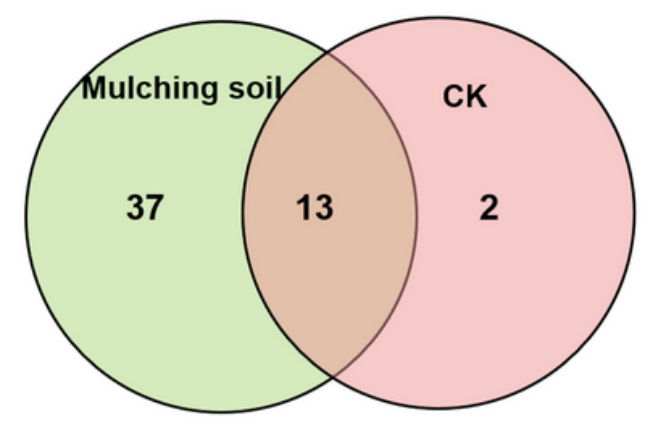

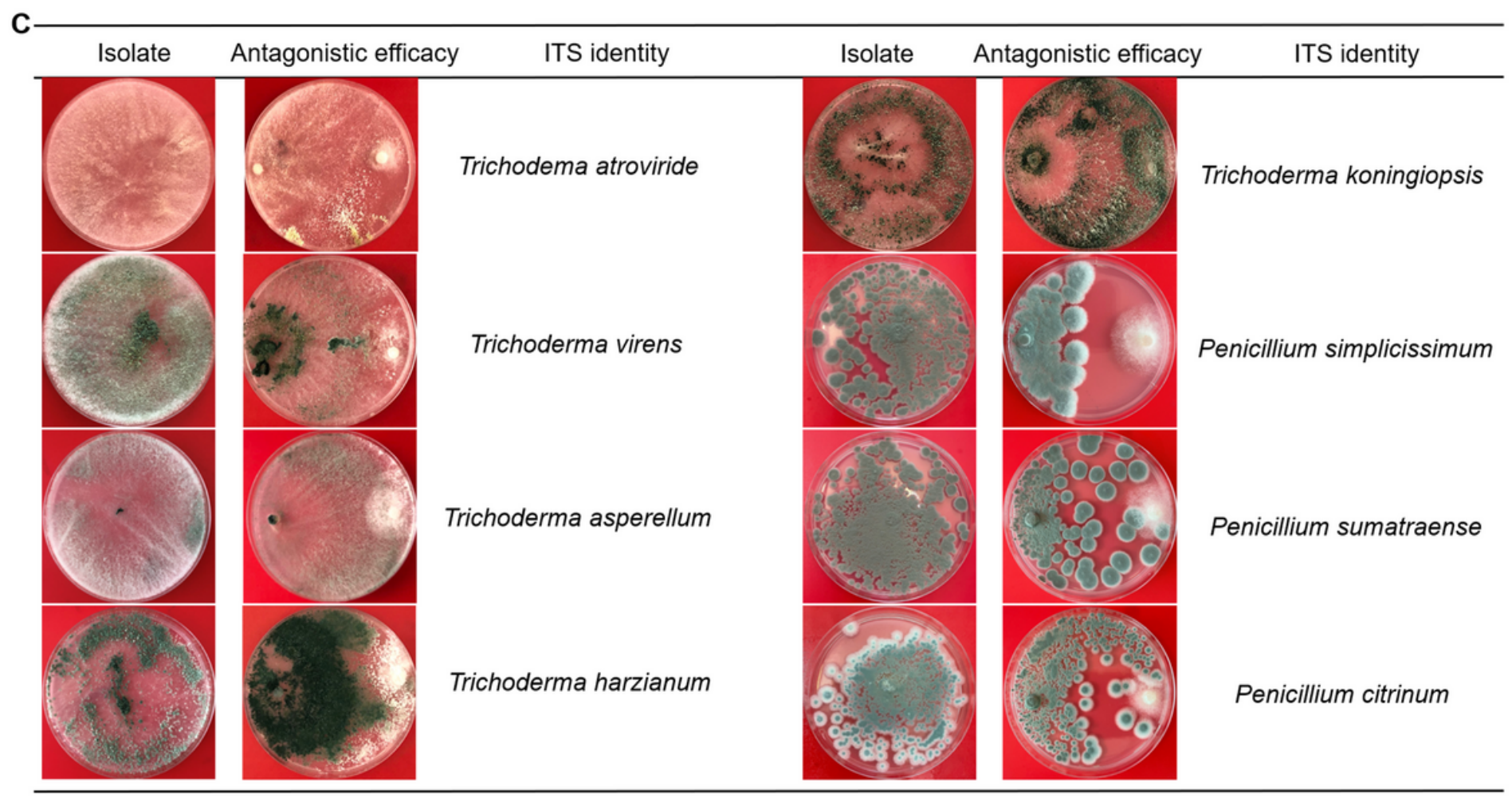

Figure 7

Screening and characterization of antagonistic fungi isolates detected in this study. A, the method of biocontrol fungi screening; $B$, Venn diagram for common and unique strains detected from mulching soils (mulching for 2 years) and control soils (CK, bare soil in conventional tillage methods); $\mathrm{C}$, Characterization of antagonistic fungi isolates detected in this study. 